\title{
Criterion-Related Validity of Knee Joint-Position-Sense Measurement Using Image Capture and Isokinetic Dynamometry
}

\author{
Nicola Relph and Lee Herrington
}

\begin{abstract}
Context: Clinicians require portable, valid, and cost-effective methods to monitor knee joint-position-sense (JPS) ability. Objective: To examine the criterion-related validity of image-capture JPS measures against an isokinetic-dynamometer (IKD) procedure. Design: Random crossover design providing a comparison of knee JPS measures from image capture and IKD procedures. Participants: 10 healthy participants, 5 female, age 28.0 $\pm 13.29 \mathrm{y}$, mass $60.3 \pm 9.02 \mathrm{~kg}$, height $1.65 \pm 0.07 \mathrm{~m}$, and 5 male, $29.6 \pm 10.74 \mathrm{y}$, mass $73.6 \pm 5.86 \mathrm{~kg}$, height $1.75 \pm 0.07$ m. Main Outcome Measures: The dependent variables were absolute error scores (AES) provided by 2 knee directions (flexion and extension). The independent variables were the method (image capture and IKD). Results: There was no significant difference between clinical and IKD AES into knee-flexion data $(P$ $=.263, r=0.55)$. There was a significant difference between clinical and IKD AES into knee-extension data $(P=.016, r=.70)$. Conclusions: Analysis of photographic images to assess JPS measurements using knee flexion is valid against an IKD positioning method, but JPS measurements using knee extension may not be valid against IKD techniques. However, photo-analysis measurements provided a lower error score using kneeextension data and thus may provide an optimal environment to produce maximal knee JPS acuity. Therefore, clinicians do not need expensive equipment to collect representative JPS ability.
\end{abstract}

Keywords: proprioception, isokinetic dynamometer, knee extension, knee flextion

Clinicians use knee joint-position-sense (JPS) measurements to assess static knee proprioception ability. ${ }^{1}$ This is an important measurement, as it can either identify patients with a JPS deficiency that may lead to an increased risk of knee injury or progress along a proprioceptive-based rehabilitation program. The traditional clinical JPS measurement technique involves passive knee movement by the clinician to a specific target angle, then active reproduction of this angle by the patient. ${ }^{1}$ Image capture can be used to collect knee position and hence knee JPS information. However, as the clinician is part of this data-collection process, measurement bias ${ }^{2}$ may be introduced to the data. Therefore, an isokinetic dynamometer (IKD) provides an alternate means to position the knee target angle, removing researcher bias. Kiran et $\mathrm{al}^{3}$ reported high correlations between concurrent measurement of JPS using an IKD, photo analysis, and electrogoniometry. However, all target knee positions were completed by the IKD arm and therefore did not replicate a typical clinical setting. Grob et $\mathrm{al}^{4} \mathrm{did}^{\mathrm{d}}$ consider the correlation between a self-built low-speed motor and

Relph is with the Dept of Medical and Sport Sciences, University of Cumbria, Carlisle, UK. Herrington is with the School of Health Science, University of Salford, Salford, UK. Address author correspondence to Nicola Relph at Nicola.Relph@ Cumbria.ac.uk. passive researcher positioning techniques on different occasions. Results indicated a poor correlation between the 2 measurements ( $r=-.2$ ), suggesting that the methods should not be used interchangeably. It is notable that when the target angle was positioned by the researcher rather than a pulley system, participants produced better JPS acuity results. However, the matching method was produced using a visual analog scale, which has limited ecological validity. ${ }^{1}$

Smith et $\mathrm{al}^{5}$ produced a systematic review on the reliability of JPS measurement techniques. Their findings suggested that intrarater reliability depended on dataacquisition techniques; image capture produced greater reliability than electrogoniometry and dynamometry. However, no study has considered the concurrent validity of assessment methods using the same participants. ${ }^{5}$ An analysis of the validity of JPS techniques is difficult, as there is no universally accepted "gold standard" method of collecting JPS data. However, the use of an IKD to position a limb at a defined angle is accepted. Therefore, criterion-related, specifically concurrent validity was investigated in this study by comparing a clinical JPS measurement technique with an IKD JPS protocol. Concurrent validity is defined as a comparison between 1 previously validated protocol and a new or previously unvalidated procedure. ${ }^{6}$ Clinicians use JPS to measure the effectiveness of a rehabilitation 
program, so it is imperative that the measurements have concurrent validity. The aim of the current study was to validate measurement of JPS using a clinical researcher passive-positioning technique versus an IKD-positioning technique.

\section{Methods}

A convenience sample of 10 healthy participants took part in the study (see Table 1 and Appendix). All were free from lower-extremity injury and neurological disease and had no previous history of significant knee injury or surgery. Participants read an information sheet and provided written informed consent. This study was approved by the university ethics board. The dependent variables were collected using IKD (Humac Norm 776, CSMi, Stoughton, MA, USA) and image-capture procedures. The image-capture equipment included a camera (Casio Exilim, EX-FC100, Casio Electronics Co, Ltd, London, UK) and a tripod (Camlink TP-2800, Camlink UK, Leicester, UK). The camera setup followed the British Association of Sport and Exercise Sciences (BASES) guidelines. $^{7}$

\section{Procedures}

The study was a random crossover design; hence, participants were tested using both methods, a week apart. Participants wore shorts and removed the sock and shoe from their dominant-leg foot. The participants were prepared for image-capture data collection by placing markers on the following anatomical points: a point on a line following the greater trochanter to the lateral epicondyle, close to the lateral epicondyle (placement of a marker directly on the greater trochanter is difficult due to clothing), the lateral epicondyle, and the lateral malleolus of the dominant leg (following Andersen et $\mathrm{al}^{8}$ ).

Each participant was seated on the end of an orthopedic assessment plinth and blindfolded (see Figure 1). The dominant leg was passively moved by the researcher through $30^{\circ}$ to $60^{\circ}$ of knee extension from a starting knee angle of $90^{\circ}$ or through $60^{\circ}$ to $90^{\circ}$ of knee flexion from a starting angle of $0^{\circ}$ to a target angle at an angular velocity of approximately $10 \%$ s. The order of the target angles was randomly allocated using randomly generated numbers. The participant then actively held the leg in this position for 5 seconds. A photograph of the leg in the target position was taken using the camera placed 3 $\mathrm{m}$ from the sagittal plane of movement on the fixed-level tripod. The leg was then passively returned to the starting angle, and the participant was instructed to actively move that leg to the target angle and hold it in this position. Another photograph was taken, and the participant instructed to move the leg back to the starting position. The process was repeated 5 times for each target angle on the dominant leg.

Knee JPS measurements were also collected using an IKD. A specific protocol was written (see Table 2) to ensure that the IKD passively moved the participant's dominant leg to the predetermined target angles. The participant was seated in the IKD chair but not secured in the chair, as this may have introduced sensory feedback from the popliteal fossa, which was not present in the clinical trials. Once the center of rotation of the dominant knee had been correctly aligned to the center of rotation of the IKD lever axis, the leg was strapped to the lever and the participant blindfolded. The IKD protocol then passively moved the leg through $30^{\circ}$ to $60^{\circ}$ of extension from a starting knee angle of $90^{\circ}$ or through $60^{\circ}$ to $90^{\circ}$

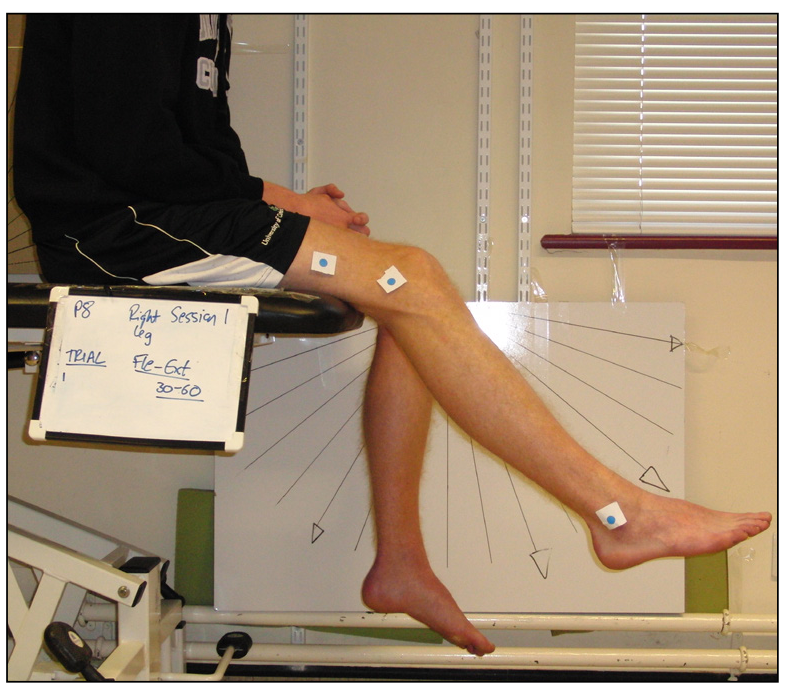

Figure 1 - Typical setup for image-capture knee-joint position-sense measurements.

Table 1 Participant Characteristics (Mean \pm SD)

\begin{tabular}{|c|c|c|c|c|c|c|c|c|}
\hline & Age (y) & Mass (kg) & Height (m) & BMI & $\begin{array}{c}\text { GPPAQ } \\
\text { range }\end{array}$ & KoOS & Lysholm & Tegner \\
\hline $\begin{array}{l}\text { Females } \\
(n=5)\end{array}$ & $28.0 \pm 13.29$ & $60.3 \pm 9.02$ & $1.65 \pm 0.07$ & $22.1 \pm 1.80$ & $\begin{array}{l}\text { Inactive to } \\
\text { active }\end{array}$ & $98.6 \pm 3.18$ & $98.8 \pm 2.68$ & $5.0 \pm 1.22$ \\
\hline $\begin{array}{l}\text { Males } \\
(\mathrm{n}=5)\end{array}$ & $29.6 \pm 10.74$ & $73.6 \pm 5.86$ & $1.75 \pm 0.07$ & $24.1 \pm 1.97$ & Active & $92.5 \pm 10.87$ & $87.6 \pm 17.5$ & $7.8 \pm 1.30$ \\
\hline
\end{tabular}

Abbreviations: BMI, body-mass index; GPPAQ, General Practitioner Physical Activity Questionnaire; KOOS, Knee injury and Osteoarthritis Outcome Score (the closer the score to 100, the better the knee condition); Lysholm, Lysholm Knee Score (the closer the score to 100, the better the knee condition); Tegner, Tegner Activity Scale (the closer the score to 10, the more physically active) (see Appendix for more details). 
Table 2 Isokinetic Dynamometer Protocol

\begin{tabular}{lcc}
\hline Action & Angle $\left(^{\circ}\right)$ & Hold time (s) \\
\hline From $0^{\circ}$ (full extension) into knee flexion & & \\
passive & $90 / 80 / 70 / 90 / 75$ & 5 \\
passive & 0 & 2 \\
active & Replication & 5 \\
passive & 0 & Back to step 1 \\
From $90^{\circ}$ into knee extension $\left(0^{\circ}\right)$ & \\
passive & $30 / 45 / 60 / 45 / 45$ & 5 \\
passive & 90 & 2 \\
active & Replication & 5 \\
passive & 90 & Back to step 1 \\
\hline Note: Passive action defines isokinetic dynamometer lever movement. Active motion defines \\
participant muscle contraction.
\end{tabular}

of flexion from a starting angle of $0^{\circ}$ to a specified target angle at an angular velocity of $2 \%$. Target angles were randomly selected across the range of motion. The leg was held in this position for 5 seconds and then returned to the starting angle. The participant was then instructed to move the leg to the target angle and hold, at which point the experimenter noted the knee angle using the IKD software. This process was repeated 5 times for both knee extension and flexion.

\section{Data Reduction}

Knee angles were measured from the image-capture data using 2-dimensional manual digitizing software (ImageJ, US National Institutes of Health, Bethesda, MD, USA, http://imagej.nih.gov/ij/, 1997). Knee JPS was calculated from the average delta scores between target and reproduction angles across 5 flexion and 5 extension trials, producing absolute error scores (AES) in which only magnitude was measured. Interexaminer and intraexaminer reliability were confirmed using intraclass correlation coefficients (ICC 2,1). ${ }^{9}$ The ICC value corresponding to interexaminer reliability was .98 , and $95 \%$ confidence intervals ranged from .96 to .99 . The ICC value for intraexaminer reliability was .96, and $95 \%$ confidence intervals ranged from .91 to .98 . Therefore it can be confirmed that interreliability and intrareliability of the data-analysis method were at an acceptable level. Test-retest reliability was confirmed before the current study; knee-extension trials provided an ICC of .89 and knee-flexion trials an ICC of 92.

AES scores from IKD data were calculated by subtracting the reproduction angle from the target angle set in the protocol. The averages of the 5 extension trials and 5 flexion trials were used for further analysis in each condition (photo analysis and IKD).

All statistical analysis was completed in SPSS (Version 19, IBM Corp, Armonk, NY, USA). The ShapiroWilk test was used to examine normality of data, which was confirmed. Related-samples $t$ tests were used to compare clinical and IKD JPS scores. An alpha level was set at $P<.05$. The corresponding $t$ statistic and degrees of freedom were used to calculate effect size $(r) .^{9}$

\section{Results}

There was no significant difference between imagecapture $\operatorname{AES}\left(3.7^{\circ} \pm 1.4^{\circ}\right)$ and $\operatorname{IKD} \operatorname{AES}\left(4.3^{\circ} \pm 1.8^{\circ}\right)$ knee-flexion data $(P=.263, r=.55)$. There was a significant difference between image-capture AES $\left(2.5^{\circ} \pm\right.$ $\left.0.7^{\circ}\right)$ and $\operatorname{IKD} \operatorname{AES}\left(4.3^{\circ} \pm 1.9^{\circ}\right)$ knee-extension data $(P$ $=.016, r=.70)$.

\section{Discussion}

Clinicians use JPS to measure the effectiveness of a rehabilitation program and identify patients who may be more at risk for knee injury, so it is imperative that the measurements be valid. Criterion-related validity was confirmed for knee-flexion JPS; there were no differences between JPS in a clinical and IKD setting $(P$ $=.263, r=.55$ ). However, knee-extension JPS using an image-capture technique was different than an IKD-based technique $(P=.016, r=.70)$. The IKD data provided significantly greater error scores than the image-capture data for knee extension. This supports previous evidence that JPS measurement techniques should not be used interchangeably; however, passive positioning by a researcher may provide a more optimal environment for maximal JPS performance. ${ }^{4}$ It is possible in the IKD setting that participants had to adapt to the addition of the lever arm increasing the mass of the leg and the torque required to extend the knee; hence, effort was not as natural when compared with the image-capture setting and ecological validity was reduced. This may not have the same effect on knee flexion, as the torque required in this direction would be assisted by gravity. Another feasible explanation was the seating in both tests. In the image-capture test condition participants were seated on the edge of a 
plinth and hence were not conscious of a back rest and could use pelvis rotation to assist knee extension and the associated hamstring lengthening. Previous research suggests heightened afferent information when muscles are lengthened..$^{10}$ In the IKD setting participants were seated on the edge of the seat and not supported by the back rest but may have been less likely to use pelvis rotation to assist knee extension and hence perhaps use a less natural (more resistance to) knee-extension movement. Therefore, a clinical setting may provide a more "optimal" environment for knee-extension JPS measurement, as ecological validity is increased.

Results of this validity study have important implications for clinicians. The image-capture measurement of knee JPS with passive positioning of target angles produced similar (knee flexion) and improved (knee extension) AES compared with the IKD setting. This suggests that a clinical measurement technique provides a more optimal environment and "best scores" for JPS than an IKD setting. Therefore, knee JPS can be measured in a clinical setting using cheap and easily accessible equipment; expensive IKD equipment is not necessary.

\section{References}

1. Beynnon BD, Renstrom PA, Konradsen L, Elmqvist LG, Gottlieb D, Dirks M. Validation of techniques to measure knee proprioception. In: Lephart SM, Fu FH, eds. Proprioception and Neuromuscular Control in Joint Stability. Champaign, IL: Human Kinetics; 2000:127-138.
2. Sica GT. Bias in research studies. Radiology. 2006; 238(3):780-789. PubMed doi:10.1148/radiol.2383041109

3. Kiran D, Carlson M, Medrano D, Smith DR. Correlation of three different knee joint position sense measures. Phys Ther Sport. 2010;11:81-85. PubMed doi:10.1016/j. ptsp.2010.06.002

4. Grob KR, Kuster MS, Higgins SA, Lloyd DG, Yata H. Lack of correlation between different measurements of proprioception in the knee. J Bone Joint Surg Br. 2002;84(4):614618. PubMed doi:10.1302/0301-620X.84B4.11241

5. Smith TO, Davies L, Hing CB. A systematic review to determine the reliability of knee joint position sense assessment measures. Knee. 2013;20(3):162-169. PubMed doi:10.1016/j.knee.2012.06.010

6. Sim J, Arnell P. Measurement validity in physical therapy research. Phys Ther. 1993;73(2):102-110. PubMed

7. Payton CJ. Motion analysis using video. In: Payton, CJ, Bartlett, RM, eds. Biomechanical Evaluation of Movement in Sport and Exercise: The British Association of Sport and Exercise Sciences Guidelines. London: Routledge; 2008:8-32.

8. Andersen SB, Terwilliger DM, Denegar CR. Comparison of open versus closed kinetic chain test positions for measuring joint position sense. J Sport Rehabil. 1995;4(3):165-171.

9. Field A. Discovering Statistics Using SPSS. London, UK: Sage; 2005.

10. Ribot-Ciscar E, Roll JP. Ago-antagonist muscle spindle inputs contribute together to joint movement coding in man. Brain Res. 1998;791(1-2):167-176. PubMed doi:10.1016/S0006-8993(98)00092-4 


\section{Appendix: Questionnaires Used to Define Participants' Knee-Function Score (KOOS and Lysholm) and Activity Level (GPPAQ and Tegner)}

\section{General Practice Physical Activity Questionnaire}

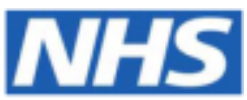

Date

Name.

1. Please tell us the type and amount of physical activity involved in your work.

\begin{tabular}{|c|l|c|}
\hline & \multicolumn{1}{|c|}{} & $\begin{array}{c}\text { Please } \\
\text { mark one } \\
\text { box only }\end{array}$ \\
\hline a & $\begin{array}{l}\text { Iam not in employment (e.g. retired, retired for health reasons, unemployed, full } \\
\text { time carer etc.) }\end{array}$ & \\
\hline b & I spend most of my time at work sitting (such as in an office) & \\
\hline c & $\begin{array}{l}\text { I spend most of my time at work standing or walking. However, my work does } \\
\text { not require much intense physical effort (e.g. shop assistant, hairdresser, } \\
\text { security guard, childminder, etc.) }\end{array}$ & $\begin{array}{l}\text { My work involves definite physical effort including handling of heavy objects and } \\
\text { use of tools (e.g. plumber, electrician, carpenter, cleaner, hospital nurse, } \\
\text { gardener, postal delivery workers etc.) }\end{array}$ \\
\hline e & $\begin{array}{l}\text { My work involves vigorous physical activity including handling of very heavy } \\
\text { objects (e.g. scaffolder, construction worker, refuse collector, etc.) }\end{array}$ & \\
\hline
\end{tabular}

2. During the last week, how many hours did you spend on each of the following activities? Please answer whether you are in employment or not

Please mark one box only on each row

\begin{tabular}{|c|l|l|l|l|l|}
\hline \multicolumn{2}{|l|}{} & None & $\begin{array}{c}\text { Some but } \\
\text { less than } \\
1 \text { hour }\end{array}$ & $\begin{array}{c}1 \text { hour but } \\
\text { less than } \\
3 \text { hours }\end{array}$ & $\begin{array}{c}\text { mours or } \\
\text { more }\end{array}$ \\
\hline a $\quad \begin{array}{l}\text { Physical exercise such as swimming, } \\
\text { jogging, aerobics, football, tennis, gym } \\
\text { workout etc. }\end{array}$ & & & & \\
\hline b & $\begin{array}{l}\text { Cycling, including cycling to work and } \\
\text { during leisure time }\end{array}$ & & & & \\
\hline c & $\begin{array}{l}\text { Walking, including walking to work, } \\
\text { shopping, for pleasure etc. }\end{array}$ & & & & \\
\hline d & Housework/Childcare & & & & \\
\hline e & Gardening/DIY & & & & \\
\hline
\end{tabular}

3. How would you describe your usual walking pace? Please mark one box only.

\begin{tabular}{|c|c|}
\hline $\begin{array}{r}\text { Slow pace } \\
(\text { i.e. less than } 3 \mathrm{mph})\end{array}$ & Steady average pace \\
\hline Brisk pace & $\begin{array}{r}\text { Fast pace } \\
\text { (i.e. over } 4 \mathrm{mph} \text { ) }\end{array}$ \\
\hline
\end{tabular}

Appendix Figure 1 - GPPAQ. Credit to the Department of Health, England. 


\section{KOOS KNEE SURVEY}

Today's date: 1 Date of birth: 1

Name:

INSTRUCTIONS: This survey asks for your view about your knee. This information will help us keep track of how you feel about your knee and how well you are able to perform your usual activities.

Answer every question by ticking the appropriate box, only one box for each question. If you are unsure about how to answer a question, please give the best answer you can.

\section{Symptoms}

These questions should be answered thinking of your knee symptoms during the last week.

S1. Do you have swelling in your knee?
Never
Rarely
Sometimes
Often
Always
ㅁ
ㅁ
ㅁ
ㅁ

S2. Do you feel grinding, hear clicking or any other type of noise when your knee moves?
Rarely
Sometimes
Oflen
Always
口
口
口
ㅁ
口

S3. Does your knee catch or hang up when moving?
Never
Rarely
Sometimes
Often
Always
口
口
口
口
口

S4. Can you straighten your knee fully?
Always
Often
Sometimes
Rarcly
Never
口
口
口
口
口

S5. Can you bend your knee fully?
Always
Often
Sometimes
Rarely
Never
口
口
ㅁ
ㅁ
ㅁ

Stiffness

The following questions concern the amount of joint stiffness you have experienced during the last week in your knee. Stiffness is a sensation of restriction or slowness in the ease with which you move your knee joint.

S6. How severe is your knee joint stiffness after first wakening in the morning?
None
Mild
Moderate
Severe
Extreme

S7. How severe is your knee stiffness after sitting, lying or resting later in the day?
None
Mild
Moderate
Severe
Extreme
口
口
口

Appendix Figure 2(a) - Knee Injury and Osteoarthritis Outcome Scale (KOOS), part 1. 
Pain

P1. How often do you experience knee pain?
Never
Monthly
Weekly
口
$\begin{array}{cc}\text { Daily } & \text { Always } \\ \text { 口 } & \text { 口 }\end{array}$

What amount of knee pain have you experienced the last week during the following activities?

P2. Twisting/pivoting on your knee
None
Mild
Moderate
Severe
Extreme
口
口
口
ㅁ
ㅁ

P3. Straightening knee fully

None Mild

Moderate

Severe

Extreme

व

口

ㅁ

口

P4. Bending knee fully

None Mild

ㅁ

Moderate

Severe

Extreme

口

口

ㅁ

ㅁ

P5. Walking on flat surface

None Mild

Moderate

Severe

Extreme

口

口

口

ㅁ

口

P6. Going up or down stairs

None Mild

Moderate

Severe

Extreme

口

口

ㅁ

口

口

P7. At night while in bed

None Mild

Moderate

Severe

Extreme

口

口

ㅁ

口

口

P8. Sitting or lying
None
Mild

ㅁ

Moderate

Severe

Extreme

ㅁ

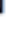

ㅁ

ㅁ

ㅁ

P9. Standing upright
None
口
Mild
Moderate
Severe
Extreme
口
口
ㅁ

Function, daily living

The following questions concern your physical function. By this we mean your ability to move around and to look after yourself. For each of the following activities please indicate the degree of difficulty you have experienced in the last week due to your knee.

A1. Descending stairs
None
Mild
Moderate
Severe
Extreme
무
口
口
口

A2. Ascending stairs

None Mild

Moderate

Severe

Extreme

ㅁ

ㅁ

ㅁ

口

Appendix Figure 2(b) - Knee Injury and Osteoarthritis Outcome Scale (KOOS), part 2. 
For each of the following activities please indicate the degree of difficulty you have experienced in the last week due to your knee.

A3. Rising from sitting
None
Mild
Moderate
Severe
Extreme
口
口
口
口
口

A4. Standing

None

Mild

Moderate

Severe

Extreme

口

ㅁ

ㅁ

口

口

A5. Bending to floor/pick up an object

$\begin{array}{ccccc}\text { None } & \text { Mild } & \text { Moderate } & \text { Severe } & \text { Extreme } \\ \mathbf{\square} & \square & \square & \square & \square\end{array}$

A6. Walking on flat surface

None Mild

ㅁ

口

Moderate

Severe

Extreme

A7. Getting in/out of car

$\begin{array}{cc}\text { None } & \text { Mild } \\ \text { 口 } & \square\end{array}$

Moderate

Severe

Extreme

ㅁ

口

ㅁ

A8, Going shopping

$\begin{array}{ccccc}\text { None } & \text { Mild } & \text { Moderate } & \text { Severe } & \text { Extreme } \\ \mathbf{\square} & \boldsymbol{\square} & \boldsymbol{\square} & \boldsymbol{\square} & \boldsymbol{\square}\end{array}$

A9. Putting on socks/stockings

$\begin{array}{ccccc}\text { None } & \text { Mild } & \text { Moderate } & \text { Severe } & \text { Extreme } \\ \mathbf{\square} & \mathbf{0} & \mathbf{\square} & \mathbf{0} & \mathbf{\square}\end{array}$

A10. Rising from bed

$\begin{array}{ccccc}\text { None } & \text { Mild } & \text { Moderate } & \text { Severe } & \text { Extreme } \\ \square & \square & \square & \square & \square\end{array}$

A11. Taking off socks/stockings

None Mild

Moderate

Severe

Extreme

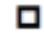

ㅁ

ㅁ

ㅁ

口

A12. Lying in bed (turning over, maintaining knee position)
None
Mild
Moderate
Severe
Extreme

A13. Getting in/out of bath

None Mild

口

口

Moderate

Severe

Extreme

A14. Sitting

None

Mild

Moderate

Severe

Extreme

A 15. Getting on/off toilet

None Mild

Moderate

Severe

Extreme

口

口

Appendix Figure 2(c) - Knee Injury and Osteoarthritis Outcome Scale (KOOS), part 3. 
For each of the following activities please indicate the degree of difficulty you have experienced in the last week due to your knee.

A 16. Heavy domestic duties (moving heavy boxes, scrubbing floors, etc)
None
Mild
Moderate
Severe
Extreme
口י
ㅁ
$\square$
ㅁ
口

A17. Light domestic duties (cooking, dusting, etc)
None
Mild
Moderate
Severe
Extreme
口
口
ㅁ
口
口

Function, sports and recreational activities

The following questions concern your physical function when being active on a higher level. The questions should be answered thinking of what degree of difficulty you have experienced during the last week due to your knee.

SP1. Squatting

None Mild

Moderate

Severe

Extreme

SP2. Running

None

Mild

Moderate

Severe

Extreme

口

口

ㅁ

ㅁ

ㅁ

SP3. Jumping

None

Mild

Moderate

Severe

Extreme

口

ㅁ

ㅁ

口

ㅁ

SP4. Twisting/pivoting on your injured knee
None
Mild
Moderate
Severe
Extreme

SP5. Kneeling None

Mild

Moderate

Severe

Extreme

ㅁ

口

ㅁ

口

口

\section{Quality of Life}

Q1. How often are you aware of your knee problem?
Never
Monthly
Weekly
Daily
Constantly
口
ㅁ
ㅁ
口
ㅁ

Q2. Have you modified your life style to avoid potentially damaging activities to your knee?

Not at al

Mildly

ㅁ

Moderately

ㅁ

Severely

口

Totally

Q3. How much are you troubled with lack of confidence in your knee?
Not at al
Mildly
Moderately
Severely
Extremely
ㅁ
ㅁ

ㅁ

口

口

Q4. In general, how much difficulty do you have with your knee?
None
Mild
Moderate
Severe
Extreme
口
ㅁ
ㅁ
ㅁ

Thank you very much for completing all the questions in this questionnaire.

Appendix Figure 2(d) - Knee Injury and Osteoarthritis Outcome Scale (KOOS), part 4. 


\section{Lysholm Knee Questionnaire / Tegner Activity Scale}

Name:

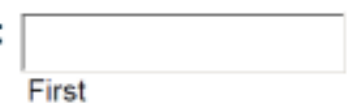

Last

Physician:

1. Limp:

(a) None

b) Slight or periodical

C) Severe and constant

\section{Support:}
( a) None
b) Stick or crutch
c) Weight-bearing impossible

\section{Locking:}

a) No locking and no catching sensations

$\mathrm{b}$ ) Catching sensation but no locking

c) Locking occasionally

d) Locking frequently

$\mathrm{Ce}$ Locked joint on examination

\section{Instability:}
a) Never giving way
$\mathrm{b})$ Rarely during athletics or other severe exertion
c) Frequently during athletics or other severe exertion (or incapable of participation)
d) Occasionally in daily activities
e) Often in daily activities
(f) Every step

Date: 090114

5. Pain:
(a) None
b) Inconstant and slight during severe exertion
c) Marked during severe exertion
d) Marked on or after walking more than $2 \mathrm{~km}$
(e) Marked on or after walking less than $2 \mathrm{~km}$
f) Constant

\section{Swelling:}
(a) None
b) On severe exertion
C) On ordinary exertion
d) Constant

\section{Stair-climbing:}
$(\mathrm{a})$ No problems
b) Slightly impaired
C) One step at a time
d) Impossible

\section{Squatting:}
a) No problems
b) Slightly impaired
c) Not beyond $90^{\circ}$
(d) Impossible

Appendix Figure 3(a) - Lysholm/Tegner Scales, part 1. 


\begin{tabular}{|c|c|c|c|}
\hline $\begin{array}{l}\text { Activity Level } \\
\text { Before Injury }\end{array}$ & $\begin{array}{c}\text { Current } \\
\text { Activity Level }\end{array}$ & $\begin{array}{l}\text { Activity Level } \\
\text { Following } \\
\text { Surgery } \\
\text { if applicable }\end{array}$ & \\
\hline & & & $\begin{array}{l}\text { Competitive sports } \\
\text { Soccer - national and international elite }\end{array}$ \\
\hline & & & $\begin{array}{l}\text { Competitive sports } \\
\text { Soccer, lower divisions } \\
\text { Ice hockey } \\
\text { Wrestling } \\
\text { Gymnastics }\end{array}$ \\
\hline & & & $\begin{array}{l}\text { Competitive sports } \\
\text { Bandy } \\
\text { Squash or badminton } \\
\text { Athletics (jumping, etc.) } \\
\text { Downhill skiing }\end{array}$ \\
\hline & & & $\begin{array}{l}\text { Competitive sports } \\
\text { Tennis } \\
\text { Athletics (running) } \\
\text { Motorcross, speedway } \\
\text { Handball } \\
\text { Basketball } \\
\text { Recreational sports } \\
\text { Soccer } \\
\text { Bandy and ice hockey } \\
\text { Squash } \\
\text { Athletics (jumping) } \\
\text { Cross-country track findings both recreational and competitive }\end{array}$ \\
\hline & & & $\begin{array}{l}\text { Recreational sports } \\
\text { Tennis and badminton } \\
\text { Handball } \\
\text { Basketball } \\
\text { Downhill sking } \\
\text { Jogging, at least five times per week }\end{array}$ \\
\hline & & & $\begin{array}{l}\text { Work Heavy labor (e.g., building, forestry) } \\
\text { Competitive sports } \\
\quad \text { Cycling } \\
\quad \text { Cross-country skiing } \\
\text { Recreational sports } \\
\quad \text { Jogging on uneven ground at least twice weekly }\end{array}$ \\
\hline & & & $\begin{array}{l}\text { Work Moderately heavy labor (e.g., truck driving, heavy domestic work) } \\
\text { Recreational sports } \\
\text { Cycling } \\
\text { Cross-country skiing } \\
\text { Jogging on even ground at least twice weekly }\end{array}$ \\
\hline & & & $\begin{array}{l}\text { Work Light labor (e.g., nursing) } \\
\text { Competitive and recreational sports } \\
\quad \text { Swimming } \\
\text { Walking in forest possible }\end{array}$ \\
\hline & & & $\begin{array}{l}\text { Work Light labor } \\
\text { Walking on uneven ground possible but impossible to walk in forest }\end{array}$ \\
\hline & & & $\begin{array}{l}\text { Work Sedentary work } \\
\text { Walking on even ground possible }\end{array}$ \\
\hline C & C & C & Sick leave or disability pension because of knee problems \\
\hline & & & Lysholm Score: 0 \\
\hline
\end{tabular}

Appendix Figure 3(b) - Lysholm/Tegner Scales, part 2. 